\title{
O Ecoturismo como experiência e prática de liberdade
}

\section{Denise Lima Rabelo}

\section{RESUMO}

De acordo com Larrosa, experiência é o que nos passa, nos acontece, nos toca! E é ele quem nos diz também que ter experiências é cada vez mais raro: o sujeito da sociedade pós-moderna convive com o excesso de trabalho e com o excesso de informação e, assim, não dispõe de tempo para o silêncio. A falta de silêncio e de memória, de acordo com Larrosa, são inimigas mortais da experiência. A vida nas cidades está se convertendo em um estado de natureza caracterizado pela regra do terror e pelo medo onipresente que a acompanha, de acordo com Baumann. E Pereira nos fala da nossa vida em condomínios, da mesmice e impessoalidade dos nossos produtos, da dificuldade de dotar um objeto de alguma característica pessoal. Fala de nós como seres confinados em espécies de prisões domiciliares... De acordo com Foucault, para cada limite que criarmos em nossa convivência social, uma possibilidade de transgressão também se desenvolverá e só uma formação como prática de liberdade pode promover uma ética e estética da existência que faz considerar a própria vida como uma obra de arte, e em que o cuidado de si e com o outro seja resultado de um modo de ver a ética. Acreditamos que o ecoturismo é um espaço/tempo de formação e pode ser experiência que contribui para tal.

PALAVRAS-CHAVE: Ecoturismo; Experiência; Liberdade.

\section{The Ecotourism as a Experience and Practice or Freedom}

\section{ABSTRACT}

According to Larrosa, experience is what we go through, what happens to us, what touches us! He also tells us that having experiences is becoming rarer: post-modern society lives overloaded with work and information, and thus has no time for silence. The lack of silence and memory, according to Larrosa, are mortal enemies of experience. Life in cities has become characterized by the rule of terror and the omnipresent fear that accompanies it, according to Baumann. Pereira tells us about our lives in condominiums, the sameness and the impersonality of our products, and the difficulty of providing an object with some personal characteristic. He speaks of us humans, as a species confined to home arrest... According to Foucault, for every limit that we create in our social life, a possibility of transgression emerges, and only the experience of freedom can promote an existence with ethics and aesthetics that considers life as a work of art, having care per se and care for others a path to what ethics is. We believe that ecotourism is a space and time learning field that allows experiences to contribute to this understanding.

KEYWORDS: Ecotourism, Experience, Freedom. 


\section{Introdução}

De acordo com Larrosa, experiência é o que nos passa, nos acontece, nos toca! E é ele quem nos diz também que ter experiências é cada vez mais raro: o sujeito da sociedade pós-moderna convive com o excesso de trabalho e com o excesso de informação e, assim, não dispõe de tempo para o silêncio. A falta de silêncio e de memória, de acordo com Larrosa (2004), são inimigas mortais da experiência.

Experiência é também aprendizagem. Viver experiências é ampliar as possibilidades de Educação. Mas quase sempre associamos a Educação somente à aquisição de conhecimentos científicos e aos espaços formais onde ele é transmitido. Quer seja em escolas, quer seja em nossas universidades, para garantir a obtenção desses conhecimentos, elabora-se o currículo, e este define, dentre outros elementos, quais os conteúdos a serem adquiridos, como se dará a avaliação, que competências e habilidades se espera que os alunos desenvolvam ao obter tal conhecimento, etc. Ou seja, há planejamento, mesmo que se assegure tempos e espaços para manifestação do imprevisto, dos acontecimentos - que também educam.

Porém o saber a ser adquirido na escola ou universidade está cada vez mais relacionado ao mercado de trabalho. Assim, os currículos estão cada vez mais comprometidos com o desenvolvimento de competências e habilidades para o bem estar individual (o indivíduo passa a ter mais chances de ingressar e ser bem sucedido no mercado de trabalho) e não social; e para o mercado, ao invés de para a vida - em especial, para a vida em comunidade.

Se o conhecimento científico é privilegiado em nossos espaços formais de Educação, temos de nos perguntar, conforme Santos: até que ponto o avanço no conhecimento técnico-científico tem contribuído para o enriquecimento ou empobrecimento prático de nossas vidas? Podemos pensar, também como Santos, que existem diferentes racionalidades que permitem o aprender: a racionalidade estéticoexpressiva da arte e da literatura; a racionalidade moral-prática da ética e do direito, e a racionalidade cognitivo-instrumental da ciência e da técnica (apud OLIVEIRA, 2008).

No que concerne à nossa vida em comunidade, é possível acumular conhecimentos formais sobre o que é o bem viver, mas, de acordo com Foucault (apud Nascimento, s/d), este bem viver em comunidade só pode ocorrer genuinamente se for resultado de uma prática de liberdade. Essa prática de liberdade é que pode fazer o indivíduo optar por uma ética e estética da existência que faz considerar a própria vida como uma obra de arte e em que o cuidado de si e com o outro é resultado de um modo de ver a ética.

Acreditamos que o ecoturismo é um espaço/tempo de formação que pode contribuir para a vivência de experiências que serão traduzidas pela racionalidade estético-expressiva e moral-prática, proporcionando um novo nascimento, como nos aponta Novelli: 
A educação proporciona o segundo nascimento do indivíduo porque o torna autônomo, senhor de si no convívio de seu povo. A autonomia é uma conquista do indivíduo porque este precisa aderir à proposta de seu povo e renunciar suas particularidades e exclusivismos. Isso não se dá no âmbito da natureza reduzida ao em si de si mesmo, ou seja, enclausurada numa existência determinada. Portanto, a educação diz respeito à existência de indivíduos e de como estes vêm a ser individualidade coletivizada e coletividade individualizada (NOVELLI, 2001, p. 72-73).

\section{Objetivos}

O objetivo deste ensaio é discutir sobre uma possibilidade de educação que não se dá na escola ou em qualquer outro ambiente formal: o ecoturismo. Não se trata, assim, de falar de educação como aquisição de habilidades e competências, de educação para formar pessoas para o mercado de trabalho, mas, sim, de viver experiência. $O$ que se busca discutir aqui é uma possibilidade livre de formação para a obtenção de uma vida plena de significado, de sentido, para uma relação ética consigo mesmo e com o outro, para romper com a disjunção provocada pela separação entre natureza e cultura, que vemos tão arraigada em nossas mentes e corações.

\section{Metodologia}

Neste ensaio, buscamos o diálogo com autores que avaliam as condições de nossa existência nesta época, que, não sem conflitos, se convencionou chamar de pós-moderna, e também com autores que pensam a educação, a ética e o ecoturismo. Buscamos apresentar uma alternativa de formação que subverte a lógica do consumismo, do imediatismo, da superficialidade, e que pode nos transformar!

\section{Discussão}

Espaço, para Michel de Certeau (apud JOSGRILBERG, 2005) é lugar praticado.Tomemos como exemplo a nossa casa: ela pode ter sido projetada por um arquiteto ou engenheiro para ter uma sala e três quartos (espaço), mas nós moradores, ao fazemos uso desse espaço, podemos transformar um desses quartos num escritório ou sala de TV. Ao alterar a proposta feita por alguém que ocupa um lugar de saber e de poder (o arquiteto ou o engenheiro) nós, pessoas comuns (não-arquitetos, nãoengenheiros), praticamos nosso espaço, inventamos a nossa vida, criamos, fazemos arte - que Certeau chamou de arte do fraco - ou seja, o homem comum dá vida ao espaço, constituindo-o em lugar praticado. Nós fazemos isso em nosso cotidiano, aqui entendido não como mera repetição, mas sim conforme Certeau - espaço e tempo do que é vivido. 
A obra de arte a seguir, de autoria de José Pereira, chama-se Cotidiano em Santo Antônio (Figura 1):

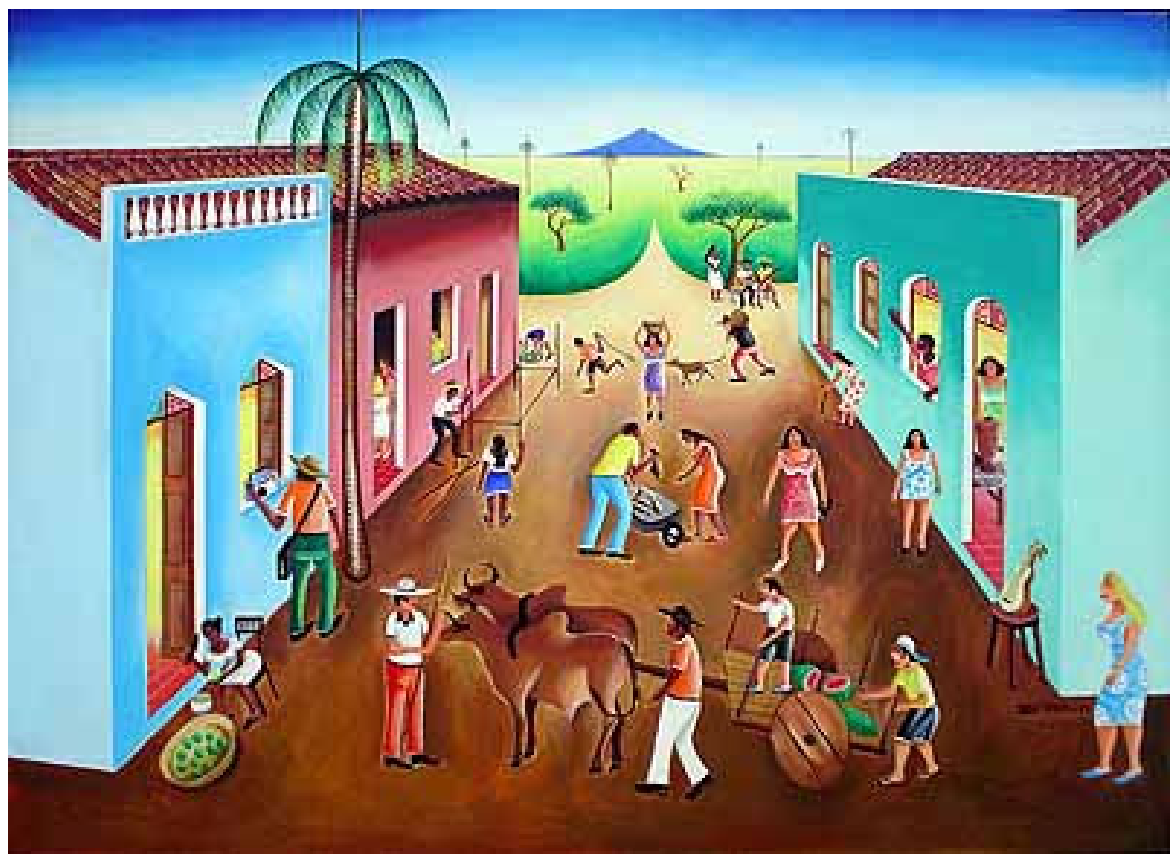

Figura 1: "Cotidiano em Santo Antônio", obra de José Pereira1.

Nesta obra, é possível ver pessoas comuns praticando seu espaço, dando-lhe vida, inventando seu cotidiano.

Essa invenção do cotidiano se dá graças ao que Certeau chama de "artes de fazer", "astúcias sutis", "táticas de resistência" que vão alterando os objetos e os códigos, e estabelecendo uma (re)apropriação do espaço e do uso ao jeito de cada um (DURAN, 2007, p. 117).

Acontece que a vida nas nossas grandes cidades não é mais assim como em Santo Antônio: ela está se convertendo em um estado de natureza caracterizado pela regra do terror e pelo medo onipresente que a acompanha, de acordo com Bauman (2009). O medo é uma constante na nossa época: medo do assalto, do trânsito, do contágio. ..., - o medo do outro.

Nas nossas grandes cidades proliferam os não-lugares. Por meio dessa negação queremos falar dos espaços onde estamos de passagem, onde somos anônimos e onde não criamos possibilidades de praticar a vida, as relações, a natureza: são os nossos transportes, é a estação do metrô, o aeroporto, os supermercados, as rodovias. De acordo com Augè $^{2}$, nestes lugares há quase sempre um texto a ser lido, que 
nos diz onde estamos, qual o caminho a seguir, em que direção está o produto de que necessitamos. Em algumas ocasiões passamos tão rápido que nem estes textos conseguimos ler (AUGÉ, 1994)!

Augè (1994) nos fala também que são duas as formas de criação de nãolugares. Uma delas está relacionada ao nosso estado de transitoriedade e a outra à nossa relação com o lugar:

\begin{abstract}
Vê-se bem que por "não-lugar" designamos duas realidades complementares, porém distintas: espaços constituídos em relação a certos fins (transporte, trânsito, comércio, lazer) e a relação que os indivíduos mantêm com esses espaços. Se as duas relações se correspondem de maneira bem ampla e, em todo caso, oficialmente (os indivíduos viajam, compram, repousam), não se confundem, no entanto, pois os não-lugares medeiam todo o conjunto de relações consigo e com os outros que só dizem respeito indiretamente a seus fins: assim como os lugares antropológicos ${ }^{3}$ criam um social orgânico, os não-lugares criam tensão solitária (AUGE, 1994, p. 87).
\end{abstract}

Essa parece ser uma palavra bem representativa da nossa época, conforme alertado por Augè, Bauman, Pereira: a solidão. O desejo de estar protegido parece conduzir irremediavelmente à necessidade de estar afastado do Outro, visto sempre como um perigo a evitar.

E Pereira (2003) nos fala da nossa vida em condomínios, da mesmice e impessoalidade dos nossos produtos, da dificuldade de dotar um objeto de alguma característica pessoal. Fala de nós como seres confinados em espécies de prisões domiciliares... E nos diz ainda:

[...] Nosso jeito de ser imita a cidade. E a cidade imita nosso jeito. [...] Concebemos a cidade em setores específicos: o bar dos mauricinhos, o clube dos negros, a boate dos veados. O bairro dos ricos, a vila dos bandidos, a rua das prostitutas. A região do comércio, a zona dos bancos, enfim. Quadriculamos, classificamos, hierarquizamos a cidade e seus lugares. Ordenamos os fluxos, o trânsito. Produzimos crachás invisíveis, uniformes, fabricamos senhas, gestos, comportamentos (PEREIRA, 2003, p. 29).

Desta forma, é nos não-lugares dos shoppings centers e semelhantes que está aparentemente a saída para aliviar a dor de estar com medo, inseguro e só: consumir. Mas já existe nome para a doença do consumismo: é a oneomania. O consumismo, em muitas situações, causa o endividamento, com todas as conseqüências mate- 
riais e emocionais que isso envolve. O excesso de consumo também pressiona desnecessariamente os recursos naturais utilizados na fabricação de novos produtos, para atender a essa necessidade constante de aquisição de algo que dê sentido à vida, além de gerar cada vez mais resíduos. São companheiras do consumismo, portanto, a destruição ambiental, o aumento da produção de resíduos, a frustração, a depressão e o sentimento de vazio.

Convém destacar que tanto o turismo convencional quanto o ecoturismo podem se configurar como atividades empresariais que estimulam o consumismo e transformam lugares em não-lugares, o que não permite viver qualquer experiência. Em ambos os casos, turismo e ecoturismo, a frustração poderá ser a mesma que se verifica ao comprar qualquer outro bem material que só oferece a possibilidade de prazer no momento de sua aquisição. No segundo caso, do ecoturismo, há inclusive uma incoerência total com a sua própria finalidade de turismo alternativo. Tendo em vista a multiplicidade de conceitos para ecoturismo, optamos por adotar o conceito a seguir, que entende o Ecoturismo como:

“... um segmento da atividade turística que utiliza, de forma sustentável, o patrimônio natural e cultural, incentiva sua conservação e busca a formação de uma consciência ambientalista através da interpretação do ambiente, promovendo o bem estar das populações envolvidas." (BRASIL, 1994)

O turismo, seja ele convencional ou alternativo, é muitas vezes divulgado como uma atividade que promove o desenvolvimento sustentável. De acordo com a WWF - Brasil:

[...] é o desenvolvimento capaz de suprir as necessidades da geração atual, sem comprometer a capacidade de atender as necessidades das futuras gerações. É o desenvolvimento que não esgota os recursos para o futuro. Essa definição surgiu na Comissão Mundial sobre Meio Ambiente e Desenvolvimento, criada pelas Nações Unidas para discutir e propor meios de harmonizar dois objetivos: o desenvolvimento econômico e a conservação ambiental (WWF, s/d).

Na prática, o conceito surge de um impasse: países mais desenvolvidos exigiam dos menos desenvolvidos a proteção de patrimônios ambientais, como a Amazônia, por exemplo; países do chamado terceiro mundo questionavam as nações industrializadas quanto ao bem estar que já haviam proporcionado às suas sociedades, bem estar que seria almejado por todos e a que todos teriam direito. Ou seja, os países em desenvolvimento exigiam o direito de destruir, como fizeram os países desenvolvidos no passado. Aparentemente, a expressão desenvolvimento sustentável aten- 
de a todos os interesses, porque em nome do desenvolvimento é possível pressionar o ambiente acima de sua capacidade; e em nome do ambiente, é possível refrear certas formas de desenvolvimento.

A expressão em si não pode ser considerada um equívoco, o que é ambíguo é a multiplicidade de significados a que está sujeita, dependendo do ponto de vista do sujeito falante. Por isso, é sempre interessante verificar qual o sentido presente na fala do nosso interlocutor, quando se refere a desenvolvimento sustentável.

Para muitos especialistas, uma forma de evitar a ambiguidade do termo é falar de sustentabilidade. Sustentável é aquilo que permanece, o que tem continuidade. Embora o termo esteja sendo apropriado por diversas áreas, até para falar em "negócios sustentáveis", ele nos induz a pensar prioritariamente na sustentabilidade do ambiente, independente do interesse que possamos ter. Assim, fica mais claro que o nosso desejo, seja de produção, seja de consumo, esbarra numa limitação: a da sustentabilidade.

Turismo sustentável, portanto, é o turismo que considera a existência de limitações. Desta forma, ele é Educação, tanto a priori quanto durante a sua realização. Vender o turismo sustentável como mais um artefato de prazer e de consumo, sem considerar a relação que o turista mantém com o lugar, é criação de não-lugares, e compromete a sustentabilidade.

No que diz respeito a patrimônio, e em especial a patrimônio natural, cabe uma reflexão a respeito do que é público e do que é privado. Público é o que pertence a todos, à sociedade, e não o que pertence ao governo ou a alguém. A privatização do espaço público atualmente é uma realidade: rodovias, por exemplo, são administradas pela iniciativa privada, que cobra pedágio para tornar a atividade interessante $e$ rentável. E assim restringimos o uso por parte do público, em alguns casos podendo chegar ao impedimento.

A privatização do espaço público é um fenômeno que se expande no modo capitalista neoliberal de ver o mundo. Por essa ótica, o Estado deve ser mínimo, já que é tradicionalmente incapaz de uma boa gestão. O mercado, porém, possuiria naturalmente os mecanismos que garantem a eficiência e eficácia dos processos, mecanismos esses profundamente enraizados nas idéias de competitividade e de lucratividade - e não de cooperação ou de bem estar.

Comprometido com a lógica neoliberal, o que se pode notar é uma visível dificuldade do poder público em desempenhar o seu papel de gestor: assumindo essa pseudoineficiência, notamos sua ausência no cuidado com os bens e serviços públicos que não tem valor de mercado, como é o caso da educação, da saúde, das unidades de conservação.

O desleixo, resultado da visão míope de que o serviço público deve atuar de forma semelhante à iniciativa privada, leva à ausência de investimentos, às dificuldades de se manter equipes de trabalho, seja pelos baixos salários ou pelas próprias 
condições de realização deste, enfim, a uma estrutura mínima de funcionamento e manutenção de serviços públicos, que funcionam de modo precário.

Observando a imagem a seguir (Figura 2), podemos pensar na dimensão da sustentabilidade associada à idéia de patrimônio natural. Podemos pensar no valor que a sustentabilidade tem, sob uma ótica não reducionista ou produtivista, como é a lógica neoliberal. Podemos pensar também na experiência que o lugar pode proporcionar:

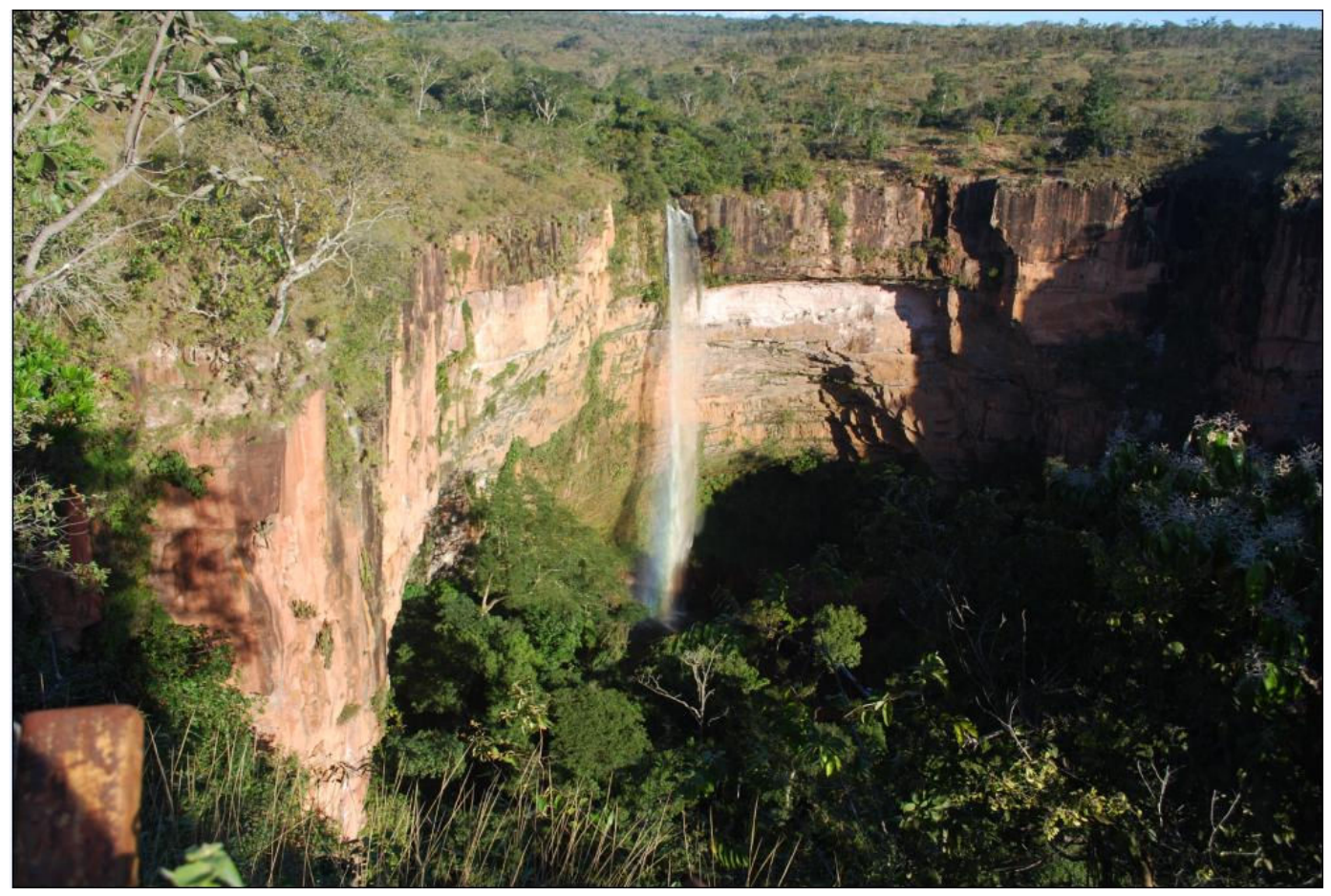

Figura 2: Imagem da Cachoeira "Véu de Noiva", Parque Nacional da Chapada dos Guimarães, no estado do Mato Grosso, Brasil ${ }^{4}$.

A brancura, a leveza e o comprimento da esteira de água levam naturalmente ao nome da cachoeira (Véu de Noiva), o que já pode ser visto como parte da própria história do lugar. Quem será que chamou assim pela primeira vez a cachoeira? Que pessoa, que povo? Que usos esses povos fizeram e fazem desse lugar? Como se chegava ou se chega até ele? Havia ou há alguma atividade religiosa neste local? Em caso positivo, por quê? Existem lendas relacionadas ao lugar? Que povos indígenas viveram ou vivem aqui? A água era reverenciada pelos povos antigos deste lugar? De que forma o turismo impacta a vida das pessoas desse lugar - negativa e positivamente?

O visitante também se depara com a grandiosidade de uma construção da qual o homem não participou, obra que levou alguns milhares de anos para ser cons- 
truída e que o ser humano pode destruir em muito pouco tempo. Que sente alguém quando se depara com essa grandiosidade? O que pode mais pensar e sentir? $\mathrm{Ne}$ nhum currículo formal poderá prever, mas certo é que essa experiência pode ser transformadora!

\section{Conclusão}

Mendonça e Neiman (2002) nos falam da necessidade do ser humano de estar em contato com a natureza, fonte da vida, e também lembram que apesar dessa necessidade, as áreas naturais vem sendo progressivamente eliminadas durante toda a nossa história. Os autores nos falam também que:

Os contos de fadas testemunham a importância psicológica das florestas para os seres humanos. Simbolizando o inconsciente, elas significam o lugar sombrio, perigoso, que transmite medo. A representação dos desafios, do enfrentamento do bem e do mal se dá, com uma enorme freqüência, em todos os povos do mundo, na floresta. Ela contém, portanto, todos os obstáculos que os humanos devem enfrentar e superar para tornarem-se reis e rainhas, autores de sua própria história pessoal (MENDONÇA; NEIMAN, p. 160).

A poética dos autores pode ser interpretada por mentes estritamente racionais e excessivamente intelectualizadas como irrelevante diante das dificuldades práticas que vivemos nos nossos cotidianos. Mas o que é a nossa vida senão o que sentimos, imaginamos e percebemos que seja a vida? Manuais tecno-científicos podem nos trazer informações úteis e práticas para utilização em nossa vida cotidiana. Porém, desconsiderar a simbologia presente no imaginário humano é considerar a cada um como um autômato, um robô.

As grandes perguntas humanas ainda são de onde viemos, e para onde vamos. E é só na grandeza dessas perguntas que o ser humano pode se sentir humano, individualidade coletivizada e coletividade individualizada. Estamos todos numa mesma aventura, a aventura de viver sem saber ao certo porque vivemos e o que acontece depois que se vai a vida. Há algo de eterno nas nossas perguntas sobre a vida e a morte.

Hoje, nas grandes cidades, vivemos afastados dos elementos naturais. Em vez de terra, asfalto. A água chega pela tubulação; não vemos o rio ou, quando o vemos, ele já não corresponde mais ao símbolo de purificação das sociedades antigas. O nosso modo de vida desencantado e triste promoveu um afastamento das possibilidades de descobertas, de fascínios que estão de alguma forma ocultos no inconsciente coletivo (MENDONÇA; NEIMAN, 2002, p. 161). Desta forma, como escape para u- 
ma situação em que aparentemente nada se pode fazer, vem a indiferença.

O ecoturismo pode transformar esse tradicional comportamento indiferente, pois ele pode ampliar a experiência. É uma oportunidade de fugir dos esquemas mentais que privilegiam a racionalidade cognitiva, podendo transformar o tradicional comportamento indiferente dos humanos.

Ao perceber mais, amplia-se a experiência. O tempo mais lento de contemplação ajuda a percepção dos ritmos e da essência das coisas, o que é raro de se poder fazer em ambientes humanizados. Usam-se muito poucos atributos como a capacidade de percepção sensorial, a consciência, a intuição, a elaboração dos sentimentos - coisas tão importantes para a vida cotidiana das pessoas, que vão determinar a relação que elas terão com os outros, com o meio natural e com o próprio mundo (MENDONÇA; NEIMAN, 2002, p. 161).

Ressalte-se nessa fala dos autores a questão do "tempo mais longo". Como dissemos no início deste ensaio, a falta de tempo da nossa época é inimiga mortal da experiência!

Ser individualidade coletivizada significa saber que se é um indivíduo único, uma obra de arte, obra de arte de si mesmo, o que não tem a ver com o individualismo; significa também saber que é nas relações que a obra de arte se faz; portanto, para os autores aqui mencionados, a experiência de estar na natureza pode ser um grande laboratório para a reformulação da questão da individualidade/individualismo, e para a nossa rehumanização (MENDONÇA; NEIMAN, 2002, p. 163).

O ecoturismo é uma possibilidade de Educação como prática de liberdade. Diferentemente dos espaços formais, onde o currículo é "veículo que contém a filosofia, a ideologia, a intencionalidade educacional", e "onde a manipulação da informação é facilmente exercitada" (BERTICELLI, 2005, p. 116), o Ecoturismo é livre; não há um resultado obrigatório e único a se obter. Na medida em que provoca experiências, 0 Ecoturismo pode ser Educação quando promove a ética do cuidado de si e do cuidado do Outro, quando muda a relação que temos com os outros, com o meio natural e com o mundo. Ou seja, quando nos toca, nos atravessa, nos transforma! 


\section{Referências Bibliográficas}

AUGĖ, M. Não-lugares: introdução à uma antropologia da supermodernidade. Campinas-SP: Papirus, 1994. (Coleção Travessia do Século)

BAUMAN, Z. Confiança e medo na cidade. Rio de Janeiro: Jorge Zahar Ed, 2009.

BERTICELLI, I.A. Currículo: tendências e filosofia. In: COSTA, M.V. O currículo nos limiares do contemporâneo. 4 ed. Rio de Janeiro: DP\&A, 2005.

BRASIL. Diretrizes para uma Política Nacional de Ecoturismo. Brasília: MICT/ MMA, 1994.

DURAN, M.C.G. Maneiras de pensar o cotidiano com Michel de Certeau. Diálogo Educ., Curitiba, v. 7, n. 22, p. 115128, set./dez. 2007.

JOSGRILBERG, F.B. Cotidiano e invenção: os espaços de Michel de Certeau. São Paulo: Escrituras Editora, 2005. Coleção Ensaios Transversais.

LARROSA, J. Linguagem e educação depois de Babel. Belo Horizonte: Autêntica, 2004.

NASCIMENTO, W.F. Nos rastros de Foucault: ética e subjetivação. Disponível em http://www.unb.br/fe/tef/filoesco/foucault/art02.html Acesso em 01/05/2009.

MENDONÇA, R.; NEIMAN, Z. Ecoturismo: discurso, desejo e realidade. In: NEIMAN, Z. (org). Meio ambiente, educação e ecoturismo. Barueri, SP: Manole, 2002.

NOVELLI, P.G. O conceito de educação em Hegel. Interface - Comunic, Saúde, Educ., v.5, n.9, p.65-88, 2001. Disponível em http://www.scielo.br/pdf/icse/v5n9/05.pdf. Acesso em 26/07/2009.

OLIVEIRA, I.B. Boaventura \& a Educação. 2 ed. Belo Horizonte: Autêntica, 2008. Coleção Pensadores e Educação.

PEREIRA, M.V. O desafio da tolerância na cidade contemporânea. In: PORTO, T. M. E. (Org.) Redes em construção: meios de comunicação e práticas educativas. Araraquara: JM Editora, 2003. p. 19-32

PIRES, P.S. Dimensões do ecoturismo. São Paulo: Ed SENAC São Paulo, 2002. 


\section{NOTAS:}

${ }^{1}$ Disponível em http://www.chapadadosguimaraes.com.br/pellegrim/josepereir.htm , acesso em 10/09/2009.

${ }^{2}$ Existem distinções entre Certeau e Augè quanto ao significado dos termos lugar e espaço. Para Augè, lugar antropológico é lugar de sentido.

${ }^{3}$ http://www.wwf.org.br/informacoes/questoes ambientais/ desenvolvimento sustentavel/ .

${ }^{4}$ Disponível em www.chapadadosguimaraes.com.br, acesso em 22/09/2009.

Denise Lima Rabelo: Instituto Estadual de Meio Ambiente e Recursos Hídricos- ES (IEMA), Universidade Federal do Espírito Santo - UFES.

Email: drabelo@iema.es.gov.br

Link para o currículo Lattes: http://lattes.cnpq.br/5064280154233568

Data de submissão: 25 de setembro 2009.

Data do aceite: 23 de dezembro de 2009. 